\title{
Scavenger receptor B2 as a receptor for hand, foot, and mouth disease and severe neurological diseases
}

\section{Seiya Yamayoshi, Ken Fujii and Satoshi Koike*}

Neurovirology Project, Tokyo Metropolitan Institute of Medical Science, Tokyo, Japan

Edited by:

Kazutaka Terahara, National Institute

of Infectious Diseases, Japan

\section{Reviewed by:}

Kazutaka Terahara, National Institute of Infectious Diseases, Japan Yorihiro Nishimura, National Institute of Infectious Diseases, Japan

\section{*Correspondence:}

Satoshi Koike, Neurovirology Project, Tokyo Metropolitan Institute of

Medical Science, 2-1-6 Kamikitazawa Setagaya-ku, Tokyo 156-8506, Japan.

e-mail:koike-st@igakuken.or.jp
Enterovirus 71 (EV71) is one of the major causative agents of hand, foot, and mouth disease (HFMD). Infection with EV71 is occasionally associated with severe neurological diseases such as acute encephalitis, acute flaccid paralysis, and cardiopulmonary failure. Because cellular receptors for viruses play an important role in cell, tissue, and species tropism, it is important to identify and characterize the receptor molecule. Recently, cellular receptors and host factors that stimulate EV71 infection have been identified. Several lines of evidence suggest that scavenger receptor class $B$, member 2 (SCARB2) plays critical roles in efficient EV71 infection and the development of disease in humans. In this review, we will summarize the findings of recent studies on EV71 infection and on the roles of SCARB2.

Keywords: EV71, SCARB2, HFMD, neurological disease

\section{INTRODUCTION}

Human enteroviruses (HEVs) are a large family of human pathogens belonging to the Picornaviridae family, and these viruses can cause a variety of diseases. HEVs are classified into four groups, species A (HEV-A) to species D (HEV-D). HEV-A is composed of at least 16 members of different serotypes: Coxsackievirus (CV) A2, CVA3, CVA4, CVA5, CVA6, CVA7, CVA8, CVA10, CVA12, CVA14, CVA16, Enterovirus 71 (EV71), EV76, EV89, EV90, and EV91 (Pallansch and Roos, 2007). The number of isolated and characterized HEV-A viruses is continually increasing (Oberste et al., 2007, 2008). Members of HEV-A are known to be causative agents of hand, foot, and mouth disease (HFMD), herpangina, respiratory disease, meningitis, and poliolike flaccid paralysis (Pallansch and Roos, 2007). EV71 and CVA16 are the major causative agents of HFMD. HFMD is normally a mild disease, but HFMD caused by EV71 is sometimes associated with severe neurological diseases such as acute fatal encephalitis, polio-like acute flaccid paralysis, and neurogenic pulmonary edema (Schmidt et al., 1974; Chumakov et al., 1979a,b; Melnick, 1984; Ho et al., 1999; Chan et al., 2000). Recently, large outbreaks of EV71 associated with severe neurological diseases have occurred repeatedly in the Asia-Pacific region (Ho et al., 1999; Komatsu et al., 1999; Ahmad, 2000; Chan et al., 2000; McMinn et al., 2001a,b; Fujimoto et al., 2002; Wang et al., 2002; De et al., 2011). EV71 has become a serious public health concern (Qiu, 2008).

Virus infection is initiated by attachment of the virus to a cellular receptor at the surface of a susceptible cell. Cellular receptors for viruses therefore play important roles in determining the cell, tissue, and species tropism and pathogenicity of viruses (Bergelson, 2010). Thus, the identification and characterization of the cellular receptor for EV71 are important steps in the elucidation of the pathogenicity of EV71. Recently, several research groups identified cellular receptors and host factors that enhance EV71 infection (Nishimura et al., 2009; Yamayoshi et al., 2009; Yang et al., 2009, 2011; Han et al., 2010). Herein, we will summarize the importance of scavenger receptor class B, member 2 (SCARB2) as a receptor for EV71.

\section{IDENTIFICATION OF SCARB2 AS A RECEPTOR FOR EV71}

Monolayer cultures of primate cells such as RD cells and Vero cells are susceptible to EV71 strains, and these cells are often used for the isolation of EV71 from clinical specimens (Mizuta et al., 2005, 2009). Mouse cells, such as L929 cells, are generally not highly susceptible to EV71 infection. Only residual virus antigenpositive cells are observed, even if the mouse cells are infected at a high multiplicity of infection. This species-specific restriction of EV71 infection is due to the absence on mouse cells of the cellular receptor that permits viral entry into cells. Yamayoshi et al. (2009) employed a strategy to identify the human EV71 receptor; this strategy is outlined in Figure 1. These researchers transfected human genomic DNA into mouse L929 cells and succeeded in selecting two L929 cell lines, Ltr051 and Ltr246, that became susceptible to EV71 among approximately 70,000 transformed cells. The integrated human gene(s) are expected to encode the EV71 receptor.

One of the transformed cell lines, Ltr051, was highly susceptible to EV71, with an infection efficiency similar to that of RD cells, whereas the other cell line, Ltr246, was susceptible to EV71 but with a lower efficiency. By microarray analysis of the RNAs expressed in the transformant cells, it was shown that Ltr051 cells carried the gene for human SCARB2. L929 cells that expressed SCARB2 constitutively (L-SCARB2 cells) were susceptible to all EV71 strains tested, irrespective of the sub-genogroup. EV71 infection in RD cells was inhibited both by anti-SCARB 2 antibodies and by soluble SCARB2. The human and monkey cell lines that are EV71-susceptible cells expressed SCARB2. These results suggest that SCARB2 plays a critical role in the EV71 infection pathway. In addition, Yamayoshi et al. (2009) found that CVA16 also uses SCARB2 as a receptor, suggesting that SCARB2 serves as a receptor for other HEV-As that cause HFMD. 


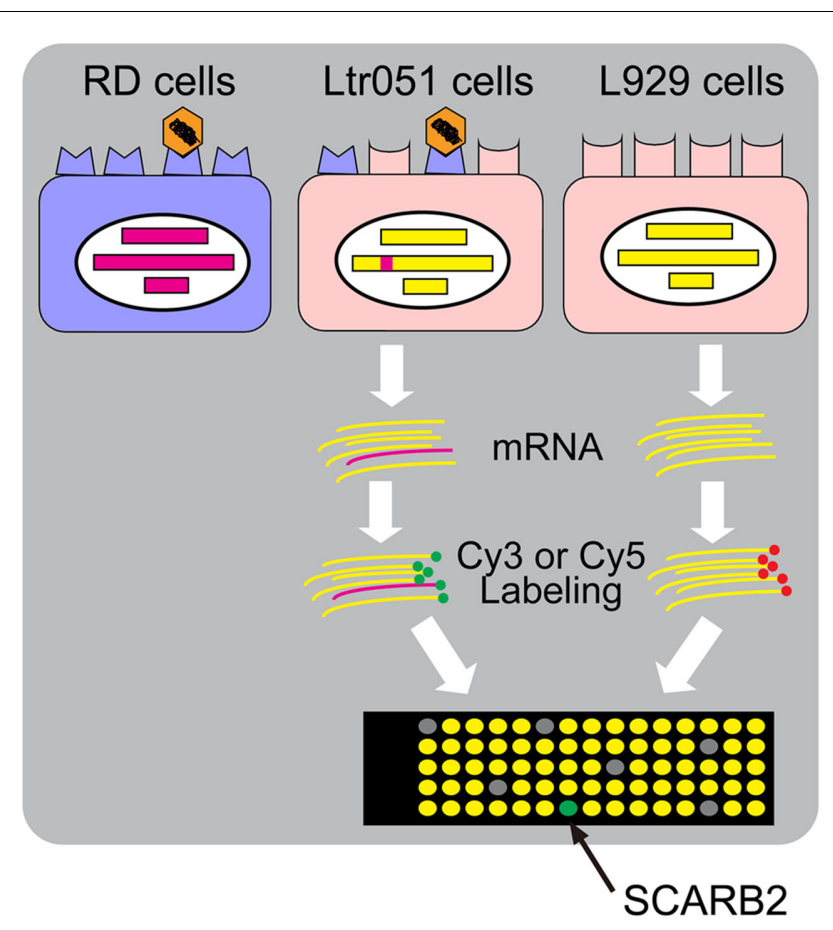

FIGURE 1 |The strategy to identify the human EV71 receptor, SCARB2. Mouse L929 cells became susceptible to EV71 when a human genomic DNA (red) was integrated into the genome (Ltr051 cells). RNA was prepared from Ltr051 cells and parental L929 cells and labeled with Cy3 or Cy5, respectively. The labeled RNAs were competitively hybridized to a microarray for human transcriptome analysis. The RNA species that were expressed in the Ltr051 cells but not in L929 cells were selected as candidates for the receptor mRNA. Each candidate was expressed in mouse L929 cells to examine the EV71 susceptibility of the transfected cells. SCARB2 expression alone was sufficient to achieve susceptibility.

The other cell line, Ltr246, is susceptible to a subset of EV71 strains but not all strains. Despite all of the efforts undertaken to identify the gene that is integrated in this cell line and that supports EV71 infection, this gene has not yet been identified. Other research groups have proposed that molecules act as receptors or other entities to enhance EV71 infection (see Mini Review by Nishimura and Shimizu, submitted). However, infection mediated by P-selectin glycoprotein ligand-1 (PSGL-1) or by an unknown molecule expressed in Ltr246 cells is not as efficient as infection mediated by SCARB2. Infection with EV71 in L929 cells expressing PSGL-1 was successful only for a subset of EV71 strains (Miyamura et al., 2011). SCARB2 seems to play the most important role in EV71 infection in vitro and in vivo because SCARB2 serves as a receptor for all EV71 strains and is expressed in the sites of EV71 replication in vivo.

\section{STRUCTURE AND FUNCTION OF SCARB2}

Scavenger receptor class $\mathrm{B}$, member 2 (also known as Lysosomal Integral Membrane Protein II, LGP85 or CD36b like-2) is composed of 478 amino acids and belongs to the CD36 family, which includes CD36 and scavenger receptor B, member 1 (SRBI and its splicing variant SR-BII; Calvo et al., 1995; Eskelinen et al., 2003). SCARB2 is one of the most abundant proteins in the lysosomal membrane and participates in membrane transportation and the reorganization of the endosomal/lysosomal compartment (Kuronita et al., 2002; Eskelinen et al., 2003; Blanz et al., 2010). SCARB2 shuttles between these compartments and the plasma membrane (Figure 2B, left; Eskelinen et al., 2003). SCARB2 is a type III double-transmembrane protein with a large extracellular domain (when it is present at the cell surface) and short cytoplasmic domains at the amino- and carboxy-terminus (Figure 2A; Calvo et al., 1995). SCARB2 is expressed in a variety of tissues, including neurons in the CNS. SCARB2 deficiency in mice causes ureteric pelvic junction obstruction, deafness, and peripheral neuropathy, and SCARB2 deficiency in humans causes action myoclonus-renal failure syndrome (AMRF; Gamp et al., 2003; Berkovic et al., 2008).

Mouse SCARB2 exhibits $85.8 \%$ amino acid identity with human SCARB2 (Figure 2A). Using chimeric mutants that include human and mouse SCARB2 sequences, Yamayoshi and Koike (2011) mapped the region that was important for efficient EV71 binding and infection. L929 cells expressing chimeras that carried amino acids 142-204 from the human sequence were susceptible to EV71, whereas chimeras that carried the mouse sequence in this region were not susceptible. It was shown that this region is also critical for binding to the virion. This region of the SCARB2 protein exhibits $76.2 \%$ amino acid identity between the human and mouse sequences. Removal of the carbohydrate moiety of the recombinant soluble SCARB2 protein by PNGase F treatment did not abolish the binding of the virus to the receptor, suggesting that the protein moiety of human SCARB2 plays a critical role in binding. Recently, Chen et al. (2012) identified critical residues required for human SCARB2 binding to EV71, which was comprised of residues 144-151 in a highly variable region among species. On the viral proteins, they showed that amino acids lined on the wall of the canyon (the EF loop of VP1) were important for SCARB2 binding and viral infectivity (Chen et al., 2012). To elucidate the mode of interaction of EV71 and SCARB2 more precisely, crystallographic analysis will be needed.

\section{MECHANISM OF EV71 INFECTION IN RD CELLS}

Hussain et al. (2011) have performed a screen of host factors required for EV71 entry into RD cells using an siRNA library. They found that the repression of genes associated with clathrinmediated endocytosis, including AP2A1, ARRB1, CLTC, CLTCL1, SYNJ1, ARPC5, PAK1, ROCK1, and WASF1, resulted in significant inhibition of EV71 infection. They observed both co-localization of EV71 with clathrin using an immunofluorescence assay and virions in clathrin-coated pits by electron microscopy. EV71 entry into cells was inhibited when a dominant-negative mutant of Eps15, which binds to AP-2, was expressed and when cells were treated with drugs that selectively inhibit clathrin-dependent endocytosis (chlorpromazine and cytochalasin B). Entry was not inhibited by drugs that inhibit caveolae-dependent endocytosis and macropinocytosis. Hussain et al. also showed that EV71 infection was abolished when cells were treated with drugs that inhibit acidification of the endosome (Bafilomycin A1 and concanamycin A). Taken together, these results suggest that the mechanism of EV71 infection is that which is summarized in Figure 2B (right). 


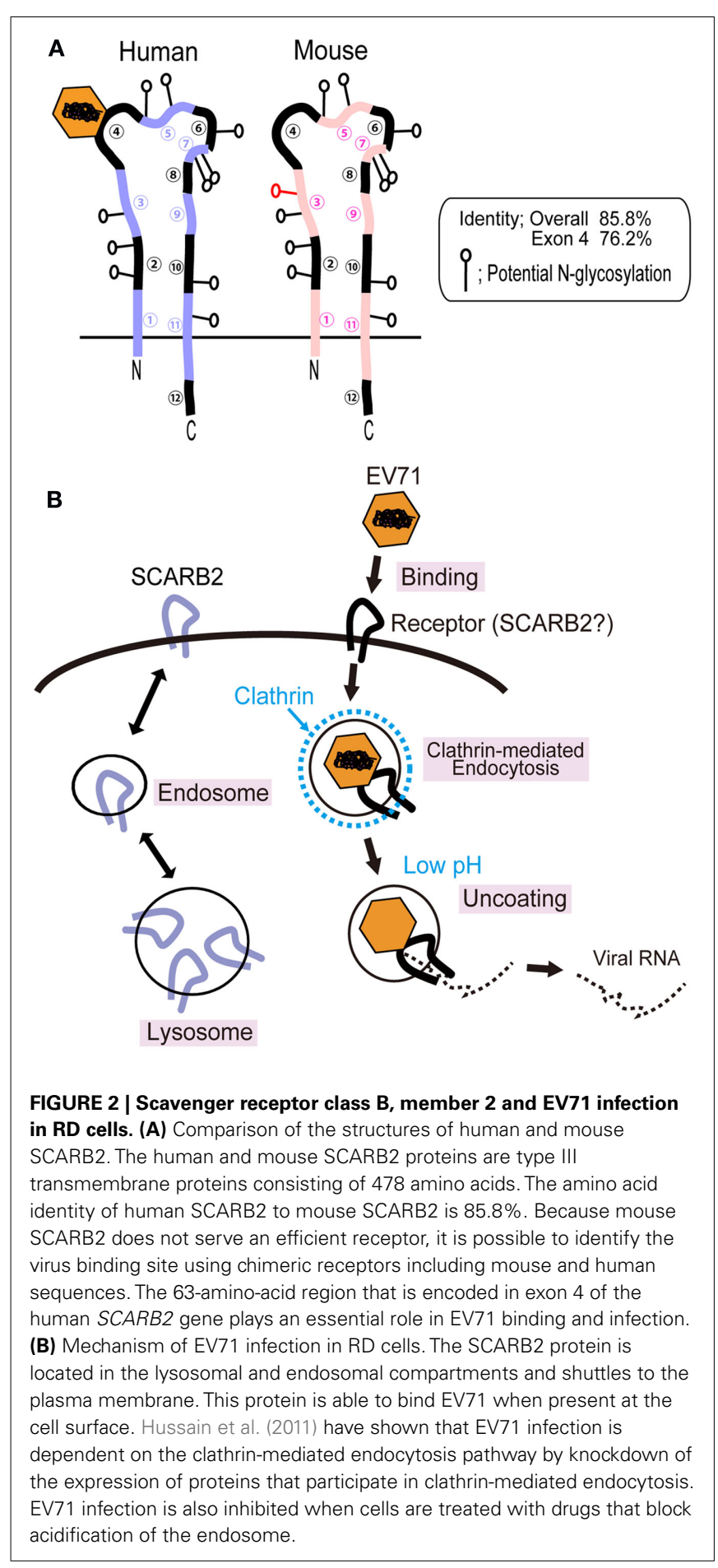

EV71 infection has been shown to be sensitive to the disruption of clathrin-mediated endocytosis and the acidic endosomal $\mathrm{pH}$. Infection of RD cells with EV71 is largely blocked by anti-SCARB2 antibody or soluble SCARB2 (Yamayoshi et al., 2009), suggesting that the SCARB2-dependent pathway is the main pathway of EV71 infection in RD cells. SCARB2 is also known to be internalized by clathrin-dependent endocytosis (Le Borgne et al., 2001; Rodionov et al., 2002). The evidence has not directly shown that SCARB2 is involved in this pathway. The involvement of SCARB2 in this pathway should be confirmed experimentally.

It is known that the poliovirus receptor (CD155) and the major group rhinovirus receptor (intercellular adhesion molecule-1) are able to bind poliovirus and rhinovirus, respectively, and induce a conformational change that leads to the uncoating of the viral genome. Chen et al. (2012) reported that SCARB2, but not PSGL1 , induced a conformational change from native $160 \mathrm{~S}$ virions to $135 \mathrm{~S}$ particles. The change was enhanced under an acidic environment (pH 5.6; Chen et al., 2012). It should be further determined whether SCARB2 induces a conformational change to empty capsids and whether VP4 is released during SCARB2-mediated conformational change.

\section{ANIMAL MODEL OF EV71 INFECTION}

To study the neuropathogenicity of EV71, experiments using live animals are essential. The most reliable animal model is the monkey model (Hashimoto et al., 1978; Chumakov et al., 1979b; Hashimoto and Hagiwara, 1982; Hagiwara et al., 1983, 1984; Nagata et al., 2002, 2004; Arita et al., 2005, 2007; Zhang et al., 2011) because the species barrier caused by receptor differences is not a critical problem. The localization patterns of EV71-induced lesions in monkeys after intraspinal and intravenous inoculation were highly consistent with those observed in humans with severe EV71 encephalitis at autopsy (Lum et al., 1998; Wang et al., 1999; Chan et al., 2000; Shieh et al., 2001). Infected monkeys showed acute flaccid paralysis, which is a sign of involvement of the pyramidal tract, and tremor and ataxia, which are signs of involvement of the extrapyramidal tract. Histopathological changes were observed in the cerebellar and pontine vestibular nuclei, and in the spinal cord. Although the monkey is an excellent model for study of EV71 neuropathogenicity, monkey models have disadvantages with respect to handling, ethics, and cost. Experiments to identify the virulence determinants in the EV71 genome are limited to one report (Arita et al., 2005).

EV71, like other CVAs, is able to infect suckling mice. Some investigators use the suckling mouse model (Chumakov et al., 1979b; Chen et al., 2004; Ong et al., 2008). A problem with this system is that mice lose susceptibility to EV71 as they age (Yu et al., 2000; Chua et al., 2008). To circumvent this problem, some research groups have isolated mouse-adapted EV71 (Wang et al., 2004, 2011; Chua et al., 2008). Khong et al. (2012) found that 2week-old mice deficient in type I and type II interferon receptors are susceptible to EV71 strains that were not artificially adapted to mice. Because mouse SCARB2 and PSGL-1 do not function as EV71 receptors in mice (Nishimura et al., 2009; Yamayoshi et al., 2009; Yamayoshi and Koike, 2011), EV71 infection in suckling mice is mediated by an unknown mechanism distinct from the SCARB2- and PSGL-1-mediated mechanisms. Indeed, EV71 exhibits different tissue tropism in suckling mice than in humans. In addition to infecting the CNS, EV71 replicates efficiently in the muscle of mice, unlike in humans (Chen et al., 2004; Wang et al., 2004; Chua et al., 2008; Ong et al., 2008).

In poliovirus, critical nucleotides or amino acids that influence the neurovirulence have been reported (Evans et al., 1985; Omata et al., 1986; Kawamura et al., 1989; Westrop et al., 1989). To identify such neurovirulence determinants in EV71, attempts were made 
to determine nucleotide changes that influence the virulence level in suckling mice (Arita et al., 2008; Chua et al., 2008; Li et al., 2011; Huang et al., 2012). Some virulence determinants were mapped to the capsid region. Because the viral capsid is involved in the binding to the receptor and in other steps of infection, such as uncoating and stabilization of the virion, it is difficult to claim that amino acid changes in the capsid region are responsible for adaptation or virulence.

One of the strategies that can be used to overcome the problems discussed above is to generate transgenic mice that express the human EV71 receptor(s). Transgenic mice expressing human PVR, CD155, are susceptible to poliovirus and are used for the

\section{REFERENCES}

Abe, S., Ota, Y., Koike, S., Kurata, T., Horie, H., Nomura, T., Hashizume, S., and Nomoto, A. (1995). Neurovirulence test for oral live polio vaccines using poliovirus-sensitive transgenic mice. Virology 206, 1075-1083.

Ahmad, K. (2000). Hand, foot, and mouth disease outbreak reported in Singapore. Lancet 356, 1338.

Arita, M., Ami, Y., Wakita, T., and Shimizu, H. (2008). Cooperative effect of the attenuation determinants derived from poliovirus sabin 1 strain is essential for attenuation of enterovirus 71 in the NOD/SCID mouse infection model. J. Virol. 82, 1787-1797.

Arita, M., Nagata, N., Iwata, N., Ami, Y., Suzaki, Y., Mizuta, K., Iwasaki, T., Sata, T., Wakita, T., and Shimizu, H. (2007). An attenuated strain of enterovirus 71 belonging to genotype a showed a broad spectrum of antigenicity with attenuated neurovirulence in cynomolgus monkeys. J. Virol. 81, 9386-9395.

Arita, M., Shimizu, H., Nagata, N., Ami, Y., Suzaki, Y., Sata, T., Iwasaki, T., and Miyamura, T. (2005). Temperaturesensitive mutants of enterovirus 71 show attenuation in cynomolgus monkeys. J. Gen. Virol. 86, 1391-1401.

Bergelson, J. M. (2010). "Receptors," in The Picornaviruses, eds E. Ehrenfeld, E. Domingo, and R. P. Roos (Washington, DC: ASM Press), 73-86.

Berkovic, S. F., Dibbens, L. M., Oshlack, A., Silver, J. D., Katerelos, M., Vears, D. F., Lullmann-Rauch, R., Blanz, J., Zhang, K. W., Stankovich, J., Kalnins, R. M., Dowling, J. P., Andermann, E., Andermann, F., Faldini, E., D’Hooge, R., Vadlamudi, L., Macdonell, R. A., Hodgson, B. L., Bayly, M. A., Savige, J., Mulley, J. C., Smyth, G. K., Power, D. A., Saftig, P., and Bahlo, M. (2008). Array-based gene discovery with three unrelated subjects shows SCARB2/LIMP-2 deficiency causes myoclonus epilepsy and glomerulosclerosis. Am. J. Hum. Genet. 82, 673-684.

Blanz, J., Groth, J., Zachos, C., Wehling, C., Saftig, P., and Schwake, M. (2010). Disease-causing mutations within the lysosomal integral membrane protein type 2 (LIMP-2) reveal the nature of binding to its ligand beta-glucocerebrosidase. Hum. Mol. Genet. 19, 563-572.

Calvo, D., Dopazo, J., and Vega, M. A. (1995). The CD36, CLA-1 (CD36L1), and LIMPII (CD36L2) gene family: cellular distribution, chromosomal location, and genetic evolution. Genomics 25, 100-106.

Chan, L. G., Parashar, U. D., Lye, M. S., Ong, F. G., Zaki, S. R., Alexander, J. P., Ho, K. K., Han, L. L., Pallansch, M. A., Suleiman, A. B., Jegathesan, M., and Anderson, L. J. (2000). Deaths of foot, and mouth disease in Sarawak, Malaysia: clinical and pathological characteristics of the disease. For the Outbreak Study Group. Clin. Infect.

Chen, P., Song, Z., Qi, Y., Feng, X., Xu, N., Sun, Y., Wu, X., Yao, X., Mao, Q., Li, X., Dong, W., Wan, X., Huang, N., Shen, X., Liang, Z., and Li, W. (2012). Molecular determinants of enterovirus 71 viral entry: a cleft around Q172 on VP1 interacts with a variable region on scavenge receptor B 2. J. Biol. Chem. [Epub ahead of print].

Chen, Y. C., Yu, C. K., Wang, Y. F., Liu, C. C., Su, I. J., and Lei, H. Y. (2004). A murine oral enterovirus 71 infection model with central nervous system involvement. J. Gen. Virol. 85, 69-77.

Chua, B. H., Phuektes, P., Sanders, S. A., Nicholls, P. K., and McMinn, P. C. (2008). The molecular basis of mouse adaptation by human enterovirus 71. J. Gen. Virol. 89, 1622-1632.

Chumakov, K. M., Lavrova, I. K., Martianova, L. I., Korolev, M. B., Bashkirtsev, V. N., and Voroshilova, children during an outbreak of hand, Dis. 31, 678-683.

study of poliovirus pathogenicity (Ren et al., 1990; Koike et al., 1991; Horie et al., 1994; Abe et al., 1995). To this end, transgenic mice that express human PSGL-1 driven by the CMV promoter were generated (Liu et al., 2011). The expression of human PSGL1 by this method was not sufficient to cause disease. It is obvious that the CMV promoter does not mimic the native PSGL-1 promoter in humans. Transgenic mice that express PSGL-1 with a distribution identical to that in human tissues are desirable. It seems that human SCARB2 expression in mice is necessary for the development of disease. A transgenic mouse model that develops disease that resembles the severe neurological diseases observed in humans will greatly contribute to the study of EV71 pathogenicity.

M. K. (1979a). Investigation of physicochemical properties of Bulgarian strain 258 of enterovirus type 71. Brief report. Arch. Virol. 60, 359-362.

Chumakov, M., Voroshilova, M., Shindarov, L., Lavrova, I., Gracheva, L., Koroleva, G., Vasilenko, S., Brodvarova, I., Nikolova, M., Gyurova, S., Gacheva, M., Mitov, G., Ninov, N., Tsylka, E., Robinson, I., Frolova, M., Bashkirtsev, V., Martiyanova, L. and Rodin, V. (1979b). Enterovirus 71 isolated from cases of epidemic poliomyelitis-like disease in Bulgaria. Arch. Virol. 60, 329-340.

De, W., Changwen, K., Wei, L., Monagin, C., Jin, Y., Cong, M., Hanri, Z., and Jun, S. (2011). A large outbreak of hand, foot, and mouth disease caused by EV71 and CAV16 in Guangdong, China, 2009. Arch. Virol. 156, 945-953.

Eskelinen, E. L., Tanaka, Y., and Saftig, P. (2003). At the acidic edge: emerging functions for lysosomal membrane proteins. Trends Cell Biol. 13, 137-145.

Evans, D. M., Dunn, G., Minor, P. D. Schild, G. C., Cann, A. J., Stanway, G., Almond, J. W., Currey, K., and Maizel, J. V. Jr. (1985). Increased neurovirulence associated with a single nucleotide change in a noncoding region of the Sabin type 3 polio vaccine genome. Nature 314 , 548-550.

Fujimoto, T., Chikahira, M., Yoshida, S. Ebira, H., Hasegawa, A., Totsuka, A., and Nishio, O. (2002). Outbreak of central nervous system disease associated with hand, foot, and mouth disease in Japan during the summer of 2000: detection and molecular epidemiology of enterovirus 71 . Microbiol. Immunol. 46, 621-627.

Gamp, A. C., Tanaka, Y., LullmannRauch, R., Wittke, D., D'hooge, R., De Deyn, P. P., Moser, T., Maier, H., Hartmann, D., Reiss, K., Illert, A. L. Von Figura, K., and Saftig, P. (2003). LIMP-2/LGP85 deficiency causes ureteric pelvic junction obstruction deafness and peripheral neuropathy in mice. Hum. Mol. Genet. 12, 631-646.

Hagiwara, A., Yoneyama, T., and Hashimoto, I. (1983). Isolation of a temperature-sensitive strain of enterovirus 71 with reduced neurovirulence for monkeys. J. Gen. Virol. 64(Pt 2), 499-502.

Hagiwara, A., Yoneyama, T., Takami, S., and Hashimoto, I. (1984). Genetic and phenotypic characteristics of enterovirus 71 isolates from patients with encephalitis and with hand, foot and mouth disease. Arch. Virol. 79, 273-283.

Han, J. F., Cao, R. Y., Deng, Y. Q., Tian, X., Jiang, T., Qin, E. D. and Qin, C. F. (2010). Antibody dependent enhancement infection of enterovirus 71 in vitro and in vivo. Virol. J. 8, 106.

Hashimoto, I., and Hagiwara, A. (1982). Pathogenicity of a poliomyelitis-like disease in monkeys infected orally with enterovirus 71: a model for human infection. Neuropathol. Appl. Neurobiol. 8, 149-156.

Hashimoto, I., Hagiwara, A., and Kodama, H. (1978). Neurovirulence in cynomolgus monkeys of enterovirus 71 isolated from a patient with hand, foot and mouth disease. Arch. Virol. 56, 257-261.

Ho, M., Chen, E. R., Hsu, K. H., Twu, S. J., Chen, K. T., Tsai, S. F., Wang, J. R., and Shih, S. R. (1999). An epidemic of enterovirus 71 infection in Taiwan. Taiwan Enterovirus Epidemic Working Group. N. Engl. J. Med. 341, 929-935.

Horie, H., Koike, S., Kurata, T., Sato-Yoshida, Y., Ise, I., Ota, Y., Abe, S., Hioki, K., Kato, H., Taya, C., Nomura, T., Hashizume, S., Yonekawa, H., and Nomoto, A. (1994). Transgenic mice carrying the human poliovirus receptor: new animal models for study of poliovirus neurovirulence. J. Virol. 68 , 681-688. 
Huang, S. W., Wang, Y. F., Yu, C. K., Su, I. J., and Wang, J. R. (2012). Mutations in VP2 and VP1 capsid proteins increase infectivity and mouse lethality of enterovirus 71 by virus binding and RNA accumulation enhancement. Virology 422, 132-143.

Hussain, K. M., Leong, K. L., Ng, M. M., and Chu, J. J. (2011). The essential role of clathrin-mediated endocytosis in the infectious entry of human enterovirus 71. J. Biol. Chem. 286, 309-321.

Kawamura, N., Kohara, M., Abe, S., Komatsu, T., Tago, K., Arita, M., and Nomoto, A. (1989). Determinants in the $5^{\prime}$ noncoding region of poliovirus Sabin 1 RNA that influence the attenuation phenotype. $J$. Virol. 63, 1302-1309.

Khong, W. X., Yan, B., Yeo, H., Tan, E. L., Lee, J. J., Ng, J. K., Chow, V. T., and Alonso, S. (2012). A non mouse-adapted enterovirus 71 (EV71) strain exhibits neurotropism causing neurological manifestations in a novel mouse model of EV71 infection. J. Virol. 86, 2121-2131.

Koike, S., Taya, C., Kurata, T., Abe, S., Ise, I., Yonekawa, H., and Nomoto, A. (1991). Transgenic mice susceptible to poliovirus. Proc. Natl. Acad. Sci. U.S.A. 88, 951-955.

Komatsu, H., Shimizu, Y., Takeuchi, Y., Ishiko, H., and Takada, H. (1999). Outbreak of severe neurologic involvement associated with enterovirus 71 infection. Pediatr. Neurol. 20, 17-23.

Kuronita, T., Eskelinen, E. L., Fujita, H., Saftig, P., Himeno, M., and Tanaka, Y. (2002). A role for the lysosomal membrane protein LGP85 in the biogenesis and maintenance of endosomal and lysosomal morphology. J. Cell. Sci. 115, 4117-4131.

Le Borgne, R., Planque, N., Martin, P., Dewitte, F., Saule, S., and Hoflack, B. (2001). The AP-3-dependent targeting of the melanosomal glycoprotein QNR-71 requires a di-leucinebased sorting signal. J. Cell. Sci. 114, 2831-2841.

Li, R., Zou, Q., Chen, L., Zhang, H., and Wang, Y. (2011). Molecular analysis of virulent determinants of enterovirus 71. PLoS ONE 6, e26237. doi:10.1371/journal.pone.0026237

Liu, J., Dong, W., Quan, X., Ma, C., Qin, C., and Zhang, L. (2011). Transgenic expression of human P-selectin glycoprotein ligand-1 is not sufficient for enterovirus 71 infection in mice. Arch. Virol. doi: 10.1007/s00705011-1198-2

Lum, L. C., Wong, K. T., Lam, S. K., Chua, K. B., Goh, A. Y., Lim, W.
L., Ong, B. B., Paul, G., Abubakar, S., and Lambert, M. (1998). Fatal enterovirus 71 encephalomyelitis. J. Pediatr. 133, 795-798.

McMinn, P., Lindsay, K., Perera, D., Chan, H. M., Chan, K. P., and Cardosa, M. J. (2001a). Phylogenetic analysis of enterovirus 71 strains isolated during linked epidemics in Malaysia, Singapore, and Western Australia. J. Virol. 75, 7732-7738.

McMinn, P., Stratov, I., Nagarajan, L., and Davis, S. (2001b). Neurological manifestations of enterovirus 71 infection in children during an outbreak of hand, foot, and mouth disease in Western Australia. Clin. Infect. Dis. 32, 236-242.

Melnick, J. L. (1984). Enterovirus type 71 infections: a varied clinical pattern sometimes mimicking paralytic poliomyelitis. Rev. Infect. Dis. 6(Suppl. 2), S387-S390.

Miyamura, K., Nishimura, Y., Abo, M., Wakita, T., and Shimizu, H. (2011). Adaptive mutations in the genomes of enterovirus 71 strains following infection of mouse cells expressing human P-selectin glycoprotein ligand-1. J. Gen. Virol. 92, 287-291.

Mizuta, K., Abiko, C., Murata, T., Matsuzaki, Y., Itagaki, T., Sanjoh, K., Sakamoto, M., Hongo, S., Murayama, S., and Hayasaka, K. (2005). Frequent importation of enterovirus 71 from surrounding countries into the local community of Yamagata, Japan, between 1998 and 2003. J. Clin. Microbiol. 43, 6171-6175.

Mizuta, K., Aoki, Y., Suto, A., Ootani, K., Katsushima, N., Itagaki, T., Ohmi, A., Okamoto, M., Nishimura, H., Matsuzaki, Y., Hongo, S., Sugawara, K., Shimizu, H., and Ahiko, T. (2009). Cross-antigenicity among EV71 strains from different genogroups isolated in Yamagata, Japan, between 1990 and 2007. Vaccine 27, 3153-3158.

Nagata, N., Iwasaki, T., Ami, Y., Tano, Y., Harashima, A., Suzaki, Y., Sato, Y., Hasegawa, H., Sata, T., Miyamura, T., and Shimizu, H. (2004). Differential localization of neurons susceptible to enterovirus 71 and poliovirus type 1 in the central nervous system of cynomolgus monkeys after intravenous inoculation. J. Gen. Virol. 85, 2981-2989.

Nagata, N., Shimizu, H., Ami, Y., Tano, Y., Harashima, A., Suzaki, Y., Sato, Y., Miyamura, T., Sata, T., and Iwasaki, T. (2002). Pyramidal and extrapyramidal involvement in experimental infection of cynomolgus monkeys with enterovirus 71. J. Med. Virol.67, 207-216.
Nishimura, Y., Shimojima, M., Tano, Y., Miyamura, T., Wakita, T., and Shimizu, H. (2009). Human Pselectin glycoprotein ligand-1 is a functional receptor for enterovirus 71. Nat. Med. 15, 794-797.

Oberste, M. S., Jiang, X., Maher, K., Nix, W. A., and Jiang, B. (2008). The complete genome sequences for three simian enteroviruses isolated from captive primates. Arch. Virol. 153, 2117-2122.

Oberste, M. S., Maher, K., and Pallansch, M. A. (2007). Complete genome sequences for nine simian enteroviruses. J. Gen. Virol. 88, 3360-3372.

Omata, T., Kohara, M., Kuge, S., Komatsu, T., Abe, S., Semler, B. L., Kameda, A., Itoh, H., Arita, M., Wimmer, E., and Nomoto, A. (1986). Genetic analysis of the attenuation phenotype of poliovirus type 1 . J. Virol. 58, 348-358.

Ong, K. C., Badmanathan, M., Devi, S., Leong, K. L., Cardosa, M. J., and Wong, K. T. (2008). Pathologic characterization of a murine model of human enterovirus 71 encephalomyelitis. J. Neuropathol. Exp. Neurol. 67, 532-542.

Pallansch, M., and Roos, R. (2007). "Enteroviruses: polioviruses, coxsackieviruses, echoviruses, and newer enteroviruses," in Fields Virology, 5th Edn, eds D. M. Knipe, P. M. Howley, D. E. Griffin, R. A. Lamb, M. A. Martin, B. Roizman, and S. E. Straus (Philadelphia: Lippincott Williams \& Wilkins), 839-893.

Qiu, J. (2008). Enterovirus 71 infection: a new threat to global public health? Lancet Neurol. 7, 868-869.

Ren, R. B., Costantini, F., Gorgacz, E. J., Lee, J. J., and Racaniello, V. R. (1990). Transgenic mice expressing a human poliovirus receptor: a new model for poliomyelitis. Cell 63, 353-362.

Rodionov, D. G., Honing, S., Silye, A., Kongsvik, T. L., Von Figura, K., and Bakke, O. (2002). Structural requirements for interactions between leucine-sorting signals and clathrin-associated adaptor protein complex AP3. J. Biol. Chem. 277, 47436-47443.

Schmidt, N. J., Lennette, E. H., and Ho, H. H. (1974). An apparently new enterovirus isolated from patients with disease of the central nervous system. J. Infect. Dis. 129, 304-309.

Shieh, W. J., Jung, S. M., Hsueh, C., Kuo, T. T., Mounts, A., Parashar, U., Yang, C. F., Guarner, J., Ksiazek, T. G., Dawson, J., Goldsmith, C., Chang, G. J., Oberste, S. M., Pallansch, M. A., Anderson, L. J., and Zaki, S. R. (2001). Pathologic studies of fatal cases in outbreak of hand, foot, and mouth disease, Taiwan. Emerging Infect. Dis. 7, 146-148.

Wang, J. R., Tuan, Y. C., Tsai, H. P., Yan, J. J., Liu, C. C., and Su, I. J. (2002). Change of major genotype of enterovirus 71 in outbreaks of hand-foot-and-mouth disease in Taiwan between 1998 and 2000. J. Clin. Microbiol. 40, 10-15.

Wang, S. M., Liu, C. C., Tseng, H. W., Wang, J. R., Huang, C. C., Chen, Y. J., Yang, Y. J., Lin, S. J., and Yeh, T. F. (1999). Clinical spectrum of enterovirus 71 infection in children in southern Taiwan, with an emphasis on neurological complications. Clin. Infect. Dis. 29, 184-190.

Wang, W., Duo, J., Liu, J., Ma, C., Zhang, L., Wei, Q., and Qin, C. (2011). A mouse muscle-adapted enterovirus 71 strain with increased virulence in mice. Microbes Infect. 13, 862-870.

Wang, Y. F., Chou, C. T., Lei, H. Y., Liu, C. C., Wang, S. M., Yan, J. J., Su, I. J., Wang, J. R., Yeh, T. M., Chen, S. H., and Yu, C. K. (2004). A mouse-adapted enterovirus 71 strain causes neurological disease in mice after oral infection. J. Virol. 78, 7916-7924.

Westrop, G. D., Wareham, K. A., Evans, D. M., Dunn, G., Minor, P. D. Magrath, D. I., Taffs, F., Marsden, S., Skinner, M. A., Schild, G. C., and Almond, J. W. (1989). Genetic basis of attenuation of the Sabin type 3 oral poliovirus vaccine. J. Virol. 63 , 1338-1344.

Yamayoshi, S., and Koike, S. (2011). Identification of a human SCARB2 region that is important for enterovirus 71 binding and infection. J. Virol. 85, 4937-4946.

Yamayoshi, S., Yamashita, Y., Li, J., Hanagata, N., Minowa, T., Takemura, T., and Koike, S. (2009). Scavenger receptor B2 is a cellular receptor for enterovirus 71. Nat. Med. 15, 798-801.

Yang, B., Chuang, H., and Yang, K. D. (2009). Sialylated glycans as receptor and inhibitor of enterovirus 71 infection to DLD-1 intestinal cells. Virol. J. 6, 141.

Yang, S. L., Chou, Y. T., Wu, C. N., and Ho, M. S. (2011). Annexin II binds to capsid protein VP1 of enterovirus 71 and enhances viral infectivity. $J$. Virol. 85, 11809-11820.

Yu, C. K., Chen, C. C., Chen, C. L., Wang, J. R., Liu, C. C., Yan, J. J., and Su, I. J. (2000). Neutralizing antibody provided protection against enterovirus type 71 lethal challenge in neonatal mice. J. Biomed. Sci. 7, 523-528.

Zhang, Y., Cui, W., Liu, L., Wang, J., Zhao, H., Liao, Y., Na, R., Dong, C., 
Wang, L., Xie, Z., Gao, J., Cui, P., Zhang, X., and Li, Q. (2011). Pathogenesis study of enterovirus 71 infection in rhesus monkeys. Lab. Invest. 91, 1337-1350.

Conflict of Interest Statement: The authors declare that the research was conducted in the absence of any commercial or financial relationships that could be construed as a potential conflict of interest.

Received: 29 December 2011; accepted: 18 January 2012; published online: 06 February 2012.
Citation: Yamayoshi S, Fujii $K$ and Koike S (2012) Scavenger receptor B2 as a receptor for hand, foot, and mouth disease and severe neurological diseases. Front. Microbio. 3:32. doi: 10.3389/fmicb.2012.00032

This article was submitted to Frontiers in Virology, a specialty of Frontiers in Microbiology
Copyright (c) 2012 Yamayoshi, Fujii and Koike. This is an open-access article distributed under the terms of the Creative Commons Attribution Non Commercial License, which permits non-commercial use, distribution, and reproduction in other forums, provided the original authors and source are credited. 